\title{
Saberes docentes na educação em privação de liberdade: um enfoque multirreferencial
}

\author{
Vanessa Goes Denardi 1 \\ Letícia Carneiro da Conceição² \\ Carolline Septimio Limeira $^{3}$
}

\section{RESUMO}

Este artigo consiste na investigação de um habitus pedagógico de atendimento educacional em contexto de privação de liberdade, buscando desvendar as relações entre escolhas curriculares e o imperativo da inclusão escolar e social. 0 ponto de reflexão situa-se na análise de saberes e sujeitos envolvidos nesta práxis, centralizando os olhares para o devir docente. As análises partiram do enfoque da multirreferencialidade, utilizando metodologia qualitativa para elaboração de entrevista semiestruturada respondida por cinco professores que atuam no Complexo Penitenciário de Florianópolis, bem como uma bricolagem com documentos e fontes levantadas. Esse estudo permitiu compreender a centralidade de uma concepção emancipatória de educação para que se atinjam os objetivos da inclusão e ressocialização.

Palavras-chave: Multirreferencialidade. Habitus. Devir.

\section{Teachers knowledge in education in detention: multi-referential approach}

\begin{abstract}
This article consists in an investigation of a pedagogical habitus of educational attendance in the context of deprivation of liberty, seeking to unravel the relations between curricular choices and the imperative of school and social inclusion. The point of reflection lies in the analysis of knowledge and subjects involved in this praxis, centering the eyes on the becoming teacher. The analyzes were based on the multireferential approach, using a qualitative methodology for the elaboration of a semistructured interview answered by five teachers who work at the Florianópolis Penitentiary Complex, as well as a bricolage with documents and sources raised. This study allowed us to understand the centrality of an emancipatory conception of education in order to achieve the goals of inclusion and resocialization.
\end{abstract}

Keywords: Multi-referentiality. Habitus. To become.

1 Doutoranda em Linguística pela Universidade Federal de Santa Catarina. Orcid iD: https://orcid.org/0000-0003-3619-4444. E-mail: goes_vanessa@hotmail.com

2 Doutoranda em Educação pela Universidade Federal do Pará. Orcid iD: https://orcid.org/0000-0002-3302-0089. E-mail: carneiroleticia1@gmail.com

3 Doutora em Educação pela Universidade do Estado de Santa Catarina. Orcid iD: https://orcid.org/0000-0003-2669-31 19. E-mail: carolpedagoga@yahoo.com.br 


\section{Saberes docentes en la educación en privación de libertad: un enfoque multirreferencial em el complejo penitenciario de florianópolis, brasil}

\section{RESUMEN}

El objetivo de este artículo es estudiar el proceso de investigación sobre un habitus pedagógico de asistencia educativa en un contexto de privación de libertad, buscando comprender la relación entre las opciones curriculares y el imperativo de la inclusión escolar y social. El punto central de la discusión radica en el análisis del conocimiento y las materias involucradas en esta praxis, centrando la discusión en el perfil del maestro que se está construyendo. Los análisis se basaron en el enfoque multirreferencial, utilizando una metodología cualitativa, a través de la elaboración de una entrevista semiestructurada aplicada a uma selección de docentes que trabajan en el Complejo Penitenciario de Florianópolis, Brasil. En este trabajo se logró comprender la centralidad de una concepción emancipadora de la educación y valorar los objetivos de inclusión escolar y resocialización en el contexto observado.

Palabras claves: Multireferencialidad. Habitus. Devenir.

\section{Introdução}

Pensar a complexidade de um campo atravessado por múltiplas dimensões, sejam elas sociais e/ou culturais, sejam políticas e/ou econômicas, é pensar nas in/exclusões que ele provoca, nos sujeitos que abrange, e na polifonia que emerge de seus caminhos sinuosos. Consoante a esses múltiplos desafios, a abordagem da multirreferencialidade se delineia como um enfoque organizador das questões demandadas pelas reflexões das políticas educacionais e curriculares, no sentido do atendimento à diversidade e às diferenças na construção de espaços mais inclusivos em situação de escolarização de privados de liberdade.

Segundo Foucault (2009, p. 218), "conhecem-se todos os inconvenientes da prisão, e sabe-se que é perigosa quando não inútil. $E$, entretanto, não 'vemos' o que pôr em seu lugar. Ela é a detestável solução, de que não se pode abrir mão". Para o autor, as prisões vêm sendo ministradas pela sociedade como remédio para seu próprio mal, com a reativação das técnicas penitenciárias como forma de corrigir seu próprio 
fracasso e a realização do projeto corretivo como o único método para superar a impossibilidade de torná-lo realidade.

\begin{abstract}
A prisão, essa região mais sombria do aparelho de justiça, é o local onde o poder de punir, que não ousa mais se exercer com o rosto descoberto, organiza silenciosamente um campo de objetividade em que o castigo poderá funcionar em plena luz como terapêutica e a sentença se inscrever entre os discursos do saber. Compreende-se que a justiça tenha adotado tão facilmente uma prisão que não fora, entretanto, filha de seus pensamentos. Ela lhe era agradecida por isso (FOUCAULT, 2009, p. 227).
\end{abstract}

É preciso educar e aprender na prisão e apesar da prisão. Essa é uma garantia legal advinda de recentes enfoques do paradigma jurídico que está ligada, em grande medida, à ressocialização e reinserção social, e objetiva a formação, a mudança de atitude e a evolução pessoal.

Assim, a motivação para este artigo deu-se a partir da reflexão e discussão sobre os desafios curriculares em tempos de in/exclusão frente aos discursos de igualdade de oportunidades. De maneira especial, pensou-se na necessidade de ajustar o olhar no papel dos docentes que lecionam para aqueles que, por diversas razões, encontram-se em situação de exclusão ou desvantagem social no Complexo Penitenciário de Florianópolis. Objetivamos, assim, instigar reflexões que possibilitem fornecer subsídios para que o atendimento educacional à diversidade de trajetórias de vida pessoal, escolar, social - possa ocorrer em consonância com as premissas do direito à vida, e em sociedade, e da própria democracia.

O Complexo Penitenciário de Florianópolis, administrado pelo DEAP (Departamento de Administração Prisional), conta com o "Programa de Educação em Espaços de Restrição e Privação de Liberdade" que é executado por intermédio do CEJA Florianópolis em consonância com a LDB 9.394/1996, ECA 8.069/1990, Resolução Nº 3 do CNE/2010 e Resolução nº 110 do CEE/2012. Tal Programa oferta vagas para todos os anos do Ensino Fundamental e Médio. Atualmente, estão matriculados em ambos os ciclos de ensino 180 alunos que são atendidos por 25 professores. Cabe ressaltar que em todo o Estado de Santa Catarina, a Educação de Jovens e Adultos é ofertada em 45 unidades prisionais e congrega em seu corpo docente um 
total de 377 professores. Além disso, a instituição conta com o "Projeto Despertar pela Leitura" que oferta 240 vagas divididas entre os presídios feminino, masculino e a penitenciária.

Partindo, portanto, desse contexto e através de uma metodologia de análise qualitativa a partir de um corpus constituído por cinco entrevistas semiestruturadas ${ }^{4}$, realizadas no ano de 2019 com professores vinculados ao CEJA (Centro de Educação de Jovens e Adultos) que atuam na instituição prisional já mencionada, aliada à bricolagem bibliográfica sobre o tema em questão, a abordagem deste estudo estrutura-se em dois planos: 1) o da multirreferencialidade como ponto norteador; e 2) o de habitus e devir docente através dos estudos de Pierre Bourdieu e Gilles Deleuze para ir além do evidente e entender a prática docente nas estruturas sociais que emergem do contexto de privação de liberdade, onde existem mundos concretos e mundos subjetivos que influenciam diretamente na geração de um habitus pedagógico.

O enfoque organizador da abordagem multirreferencial se mostrou essencial em nossa análise, uma vez que a especificidade da educação em situação de privação de liberdade se equaciona, ainda, com a pluralidade e diversidade dos sujeitos desse processo, tanto educadores quanto educandos. A multirreferencialidade, "por não se tratar tão somente de um arcabouço teórico, pelo contrário, por se apresentar visceralmente vinculada à prática, possibilita ao sujeito uma práxis e às práticas educativas, vida" (BARBOSA, 2019, p. 71).

Pensar/fazer a formação inspirada na abordagem multirreferencial implica um olhar plural sobre/com os sujeitos, do ponto de vista teórico, das vivências, dos princípios filosóficos, crenças, desejos e angústias. Essa compreensão de aprendizagem amplia a noção de sala de aula, de educação e de relação pedagógica, uma vez que a 'sala de aula' se configura para nós como todo e qualquer espaço onde se estabelece relações entre pessoas, onde, de fato, a aprendizagem e a formação ocorrem. Nessa perspectiva, não existe aprendizagem desvinculada da vida, das experiências aprendentes

\footnotetext{
${ }_{4}^{4}$ As entrevistas foram transcritas respeitando a fidelidade das falas dos professores, a fim de não obscurecer detalhes da oralidade que também podem ser passiveis de análise, e utilizadas no texto como citação direta com destaque em itálico.
} 
dos sujeitos sociais. A vida é, por assim dizer, uma sala de aula (BARBOSA, 2019, p. 54).

A multiplicidade de vozes e perspectivas, assim, está contemplada na abordagem que convida diferentes linguagens a dialogarem entre si e também com os objetos/sujeitos, assumindo suas pluralidades e heterogeneidades. "Essa diversidade de ângulos, de óticas, de perspectivas, vai acarretar, por sua vez, uma pluralidade de linguagens descritivas próprias para permitir a compreensão dessas diferentes leituras" (ARDOINO, 1998, p.37).

Garcia e Souza (2019, p. 771) ressaltam que "a oferta educativa aos privados de liberdade ainda encontra muitos entraves para ser efetivada". Segundo os autores, para que este direito seja garantido, "é necessário fomentar discussões nos espaços acadêmicos, políticos, religiosos e nos diferentes contextos, a fim de que se direcionem as políticas e ações" (GARCIA; SOUZA, 2019, p. 771).

Para refletirmos o trabalho dos docentes dentro dos espaços de privação de liberdade no Complexo Penitenciário de Florianópolis, elaboramos os questionamentos a partir da obra de Deleuze (1992), buscando "a matriz de percepções, de apreciações e de ações" (TEIVE, 2008, p. 31) que regem as condutas dos professores nesse contexto. As perguntas partem da concepção deleuziana de educação e da profissão docente:

as aulas foram uma parte da minha vida, eu as dei com paixão. Não são de modo algum como as conferências, porque implicam uma longa duração, e um público relativamente constante, às vezes durante vários anos. É como um laboratório de pesquisas: dá-se um curso sobre aquilo que se busca e não sobre o que se sabe. É preciso muito tempo de preparação para obter alguns minutos de inspiração. Fiquei satisfeito em parar quando vi que precisava preparar mais e mais para ter uma inspiração mais dolorosa (DELEUZE, 1992, p. 173).

As provocações do autor nos ajudam a pensar o ofício do professor, enfatizando não apenas a importância do que ele chama de compreensão filosófica, realizada através de conceitos, como também de uma compreensão não filosófica, que opera por "perceptos e afectos" - conjunto 
de operações ligadas ao que o autor denomina de "bloco das emoções". Para Deleuze, o aprendizado possui íntima relação com a plenitude da vida - que, como vimos, dialoga intimamente com a abordagem multirreferencial.

O que é o aprendizado? Começar, pouco a pouco, a selecionar. $O$ que é saber nadar? É saber que um corpo tem certos aspectos. Trata- -se de saber organizar um encontro. Aprender é sempre organizar um encontro. (...). Quando vocês alcançam esse saberviver, podem dizer que possuem a sua potência. Antes, só poderiam dizer que tendiam a aumentá-la (DELEUZE, 2008, p. 308).

Optou-se, dessa forma, por realizar a entrevista com cinco professores do total de vinte e cinco que lecionam na instituição, na qual foram abordadas as seguintes indagações: 1) O que significa dar aulas?; 2) Que saberes precisa ter um professor em um espaço de privação de liberdade?; 3) O que seria relevante aprender em um espaço de privação de liberdade? A escolha pelos docentes ocorreu de forma aleatória, sendo três do sexo feminino e dois do sexo masculino, priorizando apenas o critério de diversidade com relação às disciplinas lecionadas (Alfabetização, Português, Inglês, Matemática e Biologia). Apesar das entrevistas estarem regidas pelo consentimento dos professores envolvidos, preferiu-se proteger suas identidades e mencioná-los no texto com nomes fictícios. Cabe ressaltar que todos os respondentes estão incluídos na categoria ACT (Admissão de Caráter Temporário) da Secretaria de Educação do Estado de Santa Catarina e possuem entre um a seis anos de tempo de trabalho no Complexo Penitenciário, além de serem especialistas em suas áreas de ensino.

Sabemos, como ressaltam Toledo e Coutinho (2020, p. 4), que a própria concepção de uma singularidade identitária dos cursos de Licenciatura não é unânime e bem aceita pela sociedade e demais profissionais. Neste sentido, nossos questionamentos não buscaram alcançar alguma espécie de verdade única ou identidade totalizante escondida nas práticas docentes dos sujeitos entrevistados. Procuraram, sim, fomentar reflexões que nos ajudassem a pensar e vislumbrar as conexões entre os 
aspectos pedagógicos, organizacionais e políticos da atuação educativa no "Programa de Educação em Espaços de Restrição e Privação de Liberdade", do Complexo Penitenciário de Florianópolis, com a perspectiva de contemplação da diversidade e pluralidade dos sujeitos reclusos atendidos pelos professores entrevistados.

\section{Saberes e sujeitos: uma abordagem multirreferencial}

A partir do contexto da pesquisa, envolvendo educação em situação de privação de liberdade, e do contato com as múltiplas vozes dos sujeitos docentes que nela atuam, a aproximação com a multirreferencialidade foi se mostrando a mais adequada ao desafio.

Na abordagem multirreferencial assume-se que todo conhecimento humano é relativo, parcial e incompleto. É impossível se esgotar o conhecimento sobre o que quer que seja. A prática pedirá sempre novas articulações imprevisíveis a qualquer esquema de integração a priori, posto que as possibilidades de construção de novas significações são inesgotáveis. As articulações para responder a determinado problema serão feitas a depender de cada contexto ou situação e dos sujeitos aí envolvidos (FRÓES BURNHAM, 2002, p. 52).

Assentada na singularidade, que remete à historicidade de cada sujeito, a visão multirreferencial do mundo vai além da apreensão das noções teóricas fundantes da proposta, expressando-se em posturas atitudinais também singulares e plurais (BARBOSA, 2019).

Tais ações podem ser identificadas no contexto do espaço escolar, como na relação entre educador e educando - sujeitos atuando entre si e sobre si que viabilizam a aprendizagem mais importante de se fazer sujeito perante o outro, "com toda sua concretude e complexidade para que o ato educativo em sua finalidade última ocorra, pois é na relação que se estabelece entre si que (...) exercitam e desenvolvem sua condição autoral perante a vida" (BARBOSA, 2019, p. 54).

Há praticamente 23 anos na docência sempre fui aprendendo muito com meus alunos nos diferentes assuntos/temas/áreas/turmas/níveis com as quais trabalhei e que me ajudaram muito a perceber melhor 
e reavaliar sempre meu processo de ensino-aprendizagem, assim como dos meus alunos também. Ao entender melhor o processo todo sempre procuro ressignificar o conhecimento empírico trazido por cada aluno, e, que na educação de jovens e adultos é muito importante resgatar e diagnosticar para valorizar todos os saberes, assim como desmistificar as relações pré-estabelecidas entre conhecimento prévio/empírico/popular com o científico (MARIA).

Ainda no âmbito educacional, a multirreferencialidade considera como válidas as diversas matizes de conhecimento e abordagens da realidade.

Isso não significa aprofundar mais as dicotomias já existentes, mas a partir das diferenças tecer um novo conhecimento, na práxis social. Abordar os contextos educativos como multirreferenciais implica em considerar os sujeitos-aprendizes como enraizados numa realidade sócio-cultural heterogênea. É assumir a intersubjetividade, visto que implica as diferenças, como o princípio para o processo ensinoaprendizagem (MARTINS, 1999, p. 182).

Consoante à ideia de pluralidade, Ardoino (1998) afirma que a multirreferencialidade, ao ser vista como uma leitura plural, exige uma análise partindo dos objetos que se pretende uma apropriação em função de sistemas de referências supostamente diferentes. Nesse sentido, para o autor, a educação pode ser vista como uma "função social global", a qual está relacionada e é garantida pela práxis juntamente com os sujeitos e os contextos sociais.

Também nas definições curriculares e construção de novas relações com os saberes, realizadas a partir da crítica aos atuais currículos escolares, a abordagem multirreferencial pode trazer grande contribuição:

(...) o desafio que se encontra diante de nós é transformar o currículo num dos processos de construção de sujeitos sociais que através da reflexividade, da atividade deliberada e do imaginário, possam ter clareza de que tanto eles próprios quanto a sociedade é instituída pelos homens que a compõem e, por isso mesmo, apresenta a possibilidade de ser (re)criada como uma sociedade autônoma, portanto permanentemente instituinte (FRÓES BURNHAM, 1993, p. 12).

A articulação não hierárquica de saberes, que atravessa a questão curricular, demanda a ruptura com a linearidade do pensamento unitário e reducionista. Demanda, ainda, que se privilegie o heterogêneo como ponto de partida para a construção do conhecimento, reconhecendo a 
importância de olhares múltiplos para a compreensão dos fenômenos educativos:

A perspectiva multirreferencial, à medida que postula que 0 conhecimento sobre os fenômenos educativos - considerando a complexidade destes últimos - deve ser construído através da conjugação e de aproximações de diversas disciplinas, inscreve-se num universo dialético e dialetizante, no qual o pensamento e o conseqüente conhecimento são concebidos em contínuo movimento, num constante ir e vir, o que possibilitará a criação e, com ela, a própria construção do conhecimento (MARTINS, 2004, p. 90).

Esta concepção plural de educação, contrária à fragmentação dos saberes, dialoga com uma concepção mais ampla de sociedade, contrária à fragmentação dos indivíduos. A abordagem multirreferrencial / plural se torna "um dispositivo importante para apropriação de si, encadeamento de um processo de desalienação no contexto de uma sociedade contemporânea alienadora e maquínica como a que vivemos" (BARBOSA, 2019, p. 71).

A gente tem que ensinar, fazer o nosso papel lá dentro pensando no que que esse aluno vai aproveitar disso que eu quero passar pra ele. Incentivar o pensamento. Então, acho que é muito relevante a gente levar exemplos do dia a dia, do que eles já conhecem, do que já conviveram, e ensinar, passar nossa matéria de uma forma que eles compreendam, que não seja difícil pra eles, pensando no cotidiano, pensando quando eles saírem dali o que eles vão fazer com essas formações que a gente leva pra eles (ANA LUISA).

O caráter emancipatório da educação embasa nossa abordagem e dialoga com a concepção freireana de educandos como sujeitos com autonomia para pensar a si mesmos, intervir, transformar, falar sobre o fazer e também sonhar, constatar, avaliar, valorar, tomar decisões e romper com o status quo - "tarefa incomparavelmente mais complexa e geradora de novos saberes do que simplesmente a de nos adaptar a ela" (FREIRE, 1996, p. 48). Dentro desta concepção educacional e também social,

queremos indivíduos autônomos, isto é, capazes de uma atividade refletida própria. Contudo (...) os meios e os objetos dessa atividade, e mesmo (...) seus meios e métodos só podem ser fornecidos pela imaginação radical da psique. É aí que se encontra a fonte de 
contribuição do indivíduo à criação social-histórica. E é por isso que uma educação não mutilante, uma verdadeira paideia é de uma importância capital (CASTORIADIS, 1992, p. 60- 161).

Como destacado em Nunes e Leite (2019), reconhecer na fala dos excluídos a criticidade possibilita dar valor ao modo de agir e compreender as razões e significados implícitos dessas dinâmicas.

Levando em consideração o enfoque multirreferencial, na docência em qualquer ambiente educacional, prisional ou não,

- científico, o político e o afetivo devem estar intimamente articulados entre si e com o pedagógico. O domínio consistente de uma área específica supõe uma adequada compreensão da construção de seu objeto, dos diferentes enfoques metodológicos possiveis e suas respectivas bases epistemológicas, de sua lógica e de sua "linguagem". A dimensão política, em íntima relação com a científica, supõe uma perspectiva clara do papel social do conhecimento em questão, do tipo de sociedade e de homem que se quer ajudar a construir, da realidade que se quer compreender, desvelar e transformar. Supõe também uma consciência crítica sobre o papel da ciência, da educação do professor na sociedade em que vivemos (CANDAU, 1992, p. 47).

Segundo Candau (1992), saber, interação humana, envolvimento emocional, prazer e compromisso transformador são dimensões que precisam ser articuladas e permanentemente trabalhadas com a postura e o tratamento pedagógico indispensáveis a todo professor, afinal, ensinar pressupõe esta dimensão afetiva. "Dar aulas não é somente o meu trabalho, mas algo que me realiza como pessoa. É doar-se, uma troca de saberes e aprendizados" (CARLA).

Ainda de acordo com a autora, o professor constrói seu saber docente desde sua vivência como aluno, mas é nas realidades inesperadas de sua própria atuação que precisará administrar as imprevisibilidades da sala de aula e cultivar uma relação mais próxima ao educando. Silva e Cardozo (2020, p. 6) ainda ressaltam, a partir das análises de Candau, que

O processo educativo deve se pautar na interculturalidade que implica o reconhecimento da existência de múltiplas culturas, cada uma caracterizada por suas especificidades e particularidades, superando toda forma de hegemonização de uma sobre as outras, havendo troca de sentidos e valores que possam enriquecer todas (SILVA; CARDOZO, 2020, p. 6). 
Deleuze, sobre esta mesma relação de dupla troca entre educador e educando, salienta que

No momento em que atingimos a idade adulta, nossos mestres são aqueles que nos tocam com uma novidade radical, aqueles que sabem inventar uma técnica artística ou literária e encontrar as maneiras de pensar que correspondem à nossa modernidade, quer dizer, tanto às nossas dificuldades como aos nossos entusiasmos difusos (DELEUZE, 2004, p. 92).

Para Candau (1992), os saberes docentes no geral e os saberes de experiência em particular constituem o núcleo vital do saber docente, sendo o ponto de partida do diálogo com as disciplinas e saberes curriculares.

Os saberes da experiência se juntam no trabalho cotidiano e no conhecimento do meio. São saberes que brotam da experiência e são por ela validados. Incorporam-se à vivência individual e coletiva sob forma de habitus e de habilidades de saber fazer e de saber ser (CANDAU, 1992, p. 59).

São esses saberes - teóricos e práticos, advindos de naturezas distintas e em interação mútua - que moldam e constroem a trajetória e o perfil do professor, relacionados, ainda, às novas práticas de ensino alinhadas às novas demandas sociais que influenciam nas transformações da educação assim como no habitus docente.

\section{Habitus: um devir docente}

A educação, em um contexto de privação de liberdade, constitui-se como um campo altamente complexo que possui certa autonomia e regras específicas e, ao mesmo tempo, está inserida em um espaço social mais amplo que envolve, necessariamente, disputas entre os diferentes agentes para transformações ou conservações do que está posto (BOURDIEU, 2004).

Bourdieu (1994) compreende o campo como um espaço social estruturante e estruturado, um sistema de posições e disposições onde existem agentes, regras, objetivos, interesses e inversões que constantemente se relacionam; uma espécie de jogo no qual os indivíduos ocupam uma posição determinada na estrutura social e visam a aquisição de um capital 
simbólico que outorga prestígio, legitimidade, autoridade aos sujeitos que o possui. "Para que um campo funcione é preciso que haja lutas, ou seja, indivíduos que estejam motivados a jogar o jogo, dotados de habitus implicando o conhecimento e o reconhecimento das leis imanentes do jogo" (BOURDIEU, 2003, p. 42).

Ressalta-se, ainda, que essa posição é definida objetivamente em sua existência e nas determinações impostas a seus ocupantes a partir do contexto em que estão inseridos. Nesse sentido, podemos considerar os docentes de unidades prisionais como protagonistas de campo educacional específico que lutam e executam vários movimentos para permanecerem em suas posições designadas, que adotam uma posição particular, e que utilizam uma gama de estratégias para realizar sua prática pedagógica.

(...) acredito que o professor destinado a ministrar aulas em um espaço de privação de liberdade, além dessa parte acadêmica e de toda essa formação, ele ainda precisa ter um tratamento a mais, um conhecimento a mais para acrescentar à sua formação, como, por exemplo, saberes psicológicos, saberes da área social, saberes até de segurança, saberes da parte de defesa pessoal, porque o ambiente onde está o professor de privação de liberdade é um ambiente diferente de um professor que dá aula em um ambiente de sala comum, fora do espaço de privação de liberdade (JOÃO EMÍLIO).

Um conceito-chave desenvolvido por Bourdieu que nos ajuda a entender como os agentes se movimentam, aprendem, pensam ou agem dentro de um determinado campo é o de habitus. Para o autor, trata-se de um sistema de disposições adquiridas pela aprendizagem, seja ela implícita ou explícita, que atua como um conjunto de esquemas geradores, ou seja, um sistema que fomenta estratégias que podem ser objetivamente ligadas aos interesses objetivos de seus autores sem terem sido idealizadas para este fim (BOURDIEU, 1983). É

como princípio que gera e estrutura as práticas e as representações que podem ser objetivamente 'regulamentadas' e 'reguladas' sem que por isso sejam o produto de obediência de regras, objetivamente adaptadas a um fim, sem que se tenha necessidade da projeção consciente deste fim ou do domínio das operações para atingi-lo, mas sendo, ao mesmo tempo, coletivamente 
orquestradas sem serem o produto da ação organizadora de um maestro (BOURDIEU, 1994, p. 15).

Destarte, o habitus é um sistema constantemente submetido a experiências e inevitavelmente transformado por elas, da mesma forma que pode constituir uma situação e, ao mesmo tempo, ser por ela constituído. É através desse conceito, portanto, que se pode ter diferentes visões em uma mesma situação e ser levado a fazer/escolher (ou não) certas coisas (BOURDIEU, 2012). Assim, a visão e a escolha de um docente de/por uma instituição de privação de liberdade está diretamente ligada ao seu habitus e interiorizada sob forma de preferência, visto que, talvez, o que the parece mais instigante são as relações sociais que envolvem essa posição intelectualmente interessante (BOURDIEU, 2012) do que uma questão meramente salarial, por exemplo, visto que os professores que lecionam em prisões no Estado de Santa Catarina não recebem periculosidade ou qualquer outro tipo de benefício que os leve a escolher a docência em espaço de privação de liberdade ao invés de uma escola de educação básica qualquer.

[...] O adicional é somente para os "agentes operadores da execução penal", excluindo os professores que atuam intramuros como tais; que são profissionais da Secretaria de Educação e não da Secretaria responsável pela execução penal, responsabilizando a Secretaria parceira pelo não pagamento (BRASIL, 2010, p. 22).

O habitus também pode ser entendido como uma "subjetividade socializada" e, segundo Bourdieu $(1992,2012)$, sua noção é importante para lembrar que todos os agentes têm uma história e, portanto, são produtos de uma história individual e/ou coletiva que trazem em seu interior categorias de pensamento e de juízo, assim como sistemas de percepção e sistemas de valores que são produtos da incorporação de estruturas sociais. Na prática docente, o habitus permite a compreensão do mundo social, o qual aparece como evidente, livre de interrogações sobre suas próprias condições de possibilidade. Nesse viés, Bourdieu enfatiza em suas obras o peso das experiências sociais adquiridas desde o berço familiar do sujeito 
até às ações presentes, considerando-as partes estruturantes dessa trajetória que é construída socialmente e que permite um certo posicionamento diante das práticas.

Cada agente, quer saiba ou não, quer queira ou não, é produtor e reprodutor de sentido objetivo, porque suas ações e suas obras são produto de um modus operandi do qual ele não é o produtor e do qual ele não possui o domínio consciente; as ações encerram, pois, uma 'intenção objetiva' como diria a escolástica, que ultrapassa sempre as intenções conscientes (BOURDIEU, 1994, p. 15).

Ao abordar a prática docente, podemos ajustar a lupa e fazer uso de uma acepção desenvolvida por Teive (2008) a partir do conceito de Bourdieu: a de habitus pedagógico. A autora compreende que essa denominação, através do uso mais restrito do termo original, aborda "a síntese pela qual o professor produz sentidos e formas de inteligibilidade acerca da educação escolarizada, sobretudo, do modo como age objetivamente no cotidiano escolar" (TEIVE, 2008, 25).

(...) a situação que o aluno está é uma situação difícil e que eu não posso, digamos, oprimi-lo, porque se não aquele ambiente vai ficar hostil pra ele. Então eu tenho que ser o mais calmo, tranquilo, paciente... tento ensinar de forma mais agradável possível pra que aquele momento da aula não seja um momento ruim pra ele, que ele tenha interesse em frequentar as aulas (JOÃO EMÍLIO).

Dessa forma, o habitus pedagógico em um contexto de privação de liberdade pode se manifestar como a compreensão da situação com um sentido prático, livre de preconceitos, que permite distinguir e selecionar características ou ações pertinentes à singularidade dos alunos e do ambiente, partindo de uma lógica prática e engendrada de sentidos, cujo domínio é constitutivo da trajetória do professor envolvido, o qual passa a ser considerado um tipo muito particular de docente.

Ser que se reduz a um ter, a um ter sido, ter feito ser, o habitus é o produto do trabalho de inculcação e de apropriação necessário para que as estruturas objetivas consigam reproduzir-se, sob a forma de disposições duráveis, em todos os indivíduos submetidos aos mesmos condicionamentos, colocados, portanto, nas mesmas condições de existência (BOURDIEU, 1994, p. 78-79). 
Mister destacar que Bourdieu (1994) percebe o habitus vinculado a duas formas: a objetiva, que se refere ao campo social ao qual o sujeito pertence; e a subjetiva, que diz respeito à percepção do sujeito a esse campo. Nessa perspectiva, o habitus é entendido como o modo de pensar ou agir a partir da posição que um agente ocupa dentro de um campo, sendo esse agente passível de compartilhar esse habitus com outras pessoas através da percepção de uma mesma concepção de mundo e seu papel frente a ela, o que ocasiona que se comportem de maneira semelhante ao compartilharem certos espaços - privilegiados para reflexões e intervenções na prática pedagógica concreta (CANDAU, 1992) - ou experiências em um contexto social, que torna-se produto da socialização da pessoa como tal. Esse compartilhamento de habitus e trajetórias, bem como da própria práxis, pode ocorrer durante as formações continuadas, como salienta uma das professoras entrevistadas.

Nós, professores, tivemos a oportunidade de receber uma formação nesse nível por meio da UDESC/SED/TJSC, através do programa de extensão "Novos Horizontes", o que permitiu ao grupo de docentes de 2017-2018 uma formação bastante ampla com discussões acerca de diferentes temas relacionados, com rodas de conversas com diretores e agentes penitenciários, defensores públicos, juízes, educadores, pesquisadores e afins que aprofundam e defendem, assim como nós professores, de que a educação em espaços de privação de liberdade é muito significativa e norteadora de novos caminhos (LUANA).

Logo, é possível inferir que os professores que lecionam em prisões formam uma classe social dentro de um mesmo campo e, por isso, partilham de um habitus comum - o pedagógico - com homogeneidade nas disposições, nas escolhas e nas preferências que, somadas, tornam-se produtos de suas trajetórias. Temos, portanto, uma espécie de afinidade de habitus.

(...) a identidade das condições de existência tende a produzir sistemas de disposições semelhantes (pelo menos parcialmente), a homogeneidade (relativa) dos habitus que delas resulta está no princípio de uma harmonização objetiva das práticas e das obras, harmonização esta própria a lhes conferir a regularidade e a objetividade que definem sua 'racionalidade' específica e que as 
fazem ser vividas como evidentes e necessárias, isto é, como imediatamente inteligíveis e previsíveis, por todos os agentes dotados do domínio prático do sistema de esquemas de ação e de interpretação objetivamente implicados na sua efetivação, e por esses somente (BOURDIEU, 1994, p. 66).

O habitus pedagógico dentro de um espaço de privação de liberdade pode ser entendido como um sistema de categorias que funcionam como esquemas de percepção que permitem aos agentes/docentes conhecer, pensar e realizar distinções conjuntamente, visto que consideramos que as práticas constituem e são constituídas de forma contínua (BOURDIEU, 1987). Nesse viés, os professores, necessariamente, precisam estar munidos de uma gama de representações sobre a realidade educacional e de saberes que vão muito além dos que envolvem a disciplina ministrada. Tratam-se de saberes sistemáticos e práticos voltados à educação em ambientes prisionais, como normativas, leis, teorias pedagógicas e didáticas próprias, e metodologia que visem o real aprendizado diante das condições em que o aluno se encontra. Uma espécie de aprender e desaprender que objetiva o aprimoramento da formação (CANDAU, 1992).

[...] Importante conhecer as políticas públicas para o setor assim como as leis, recomendações, outros espaços, projetos, enfim, o que é preciso saber, conhecer para melhorar. [...] Outra sugestão seria uma maior parceria entre as instituições que promovem a educação nesses espaços para apoio e fomento à pesquisa para o corpo docente, assim como maior acompanhamento e visibilidade das ações desenvolvidas (LUANA).

Eu acho que o professor tem que ter todos os saberes, porque não adianta só ter o saber pedagógico, o saber didático, ou o saber da experiência; porque nesses espaços a gente lida com muita coisa, a gente lida com outro tipo de aluno, que já tem uma vida sofrida, que já está num local privado de liberdade... então, temos que saber adequar o conteúdo que queremos passar pra esse aluno, não esquecendo da origem dele, não esquecendo o que ele vive no dia a dia, não esquecendo que ele vai sair dali e que muitos, que a gente sabe, querem uma oportunidade. Então, a gente tem que saber um pouco de cada coisa (ANA LUISA).

Ter que saber. Vemos que a professora entende que precisa ter o domínio de saberes, pois nesses espaços é muito para dar conta. Saber 
didático, pedagógico, saber da experiência. Atrelado a esses saberes, existem outros dois que anelamos observar quando a professora diz "temos que saber adequar o conteúdo que queremos passar pra esse aluno, não esquecendo a origem dele". Nesse momento, observamos dois saberes na fala de Ana Luisa: saber a distância entre o saber que é do aluno e o saber que é do professor; e saber quais saberes o aluno tem capacidade de saber.

Rancière (2015) nos alerta que a explicação supõe que o aluno se aproxime da perfeição ao se afastar de sua origem, crescendo com a orientação dada pelo professor. Tal explicação tinha o objetivo de mostrar ao aluno sua ignorância. Nesse sentido, o autor nos lembra que o aperfeiçoamento da instrução nada mais é que o aperfeiçoamento das coleiras, ou da representação da utilidade delas.

É justamente na tentativa de ser um bom professor que o mestre embrutece sua prática. Para Rancière (2015), a explicação é o mito da pedagogia é o próprio laço da ordem social, pois estabelecendo a ideia de progresso e evolução de saberes, estabelecemos também a instrução como eternização da desigualdade.

Quem estabelece a igualdade como objetivo a ser atingido, a partir da situação de desigualdade, de fato a posterga até 0 infinito. A igualdade jamais vem após, como resultado a ser atingido. Ela deve sempre ser colocada antes (...). Deve, portanto, ser já igual a seu mestre, para submeter-se a ele (RANCIÈRE, 2015, p.11).

Nas palavras da professora Ana Luisa verificamos que há preocupação em contextualizar os conteúdos. Por outra via, percebemos também o estabelecimento de que o aluno não entenderá a menos que o saber seja apropriado a sua condição. A hierarquia de inteligências supõe explicação, supõe entender que o professor possui os mecanismos para saber como e de que forma seu aluno entenderá melhor. Nos dizeres de Rancière (2015, p. 162) "Uma desigualdade que não tem outra explicação, senão sua própria existência".

Por outro lado, nessa relação professor-aluno, o esquema perceptivo do docente baseia-se em um provável devir sobre aquilo que ele ensina e que, ao mesmo tempo, ajuda a realizar. Assim, o habitus pedagógico 
permite "reativar o sentido objetivado" na escola dentro do Complexo Penitenciário e, por sua vez, realizar "revisões e as transformações que são a contrapartida e a condição da reativação", ou seja, ajuda a manter a instituição ativa em prol de uma educação de qualidade e, sobretudo, ressocializadora que leve a sério a "magia performativa do social" (BOURDIEU, 2009, p. 94).

A gente, dentro de sala de aula, entra em um outro mundo, somos nós e os alunos. A gente nunca está preparado... podemos preparar a aula, mas cada aula vai ser diferente, uma experiência diferente, uma experiência nova... então, acho que pra mim dar aula é tudo. É muito importante, não só para o aluno, mas também pra gente como professor. Acho que a gente cresce como pessoa cada vez que a gente pisa em sala de aula. Então, é algo enriquecedor (ANA LUISA).

Dessarte, como parte constitutiva de seu habitus, o docente que atua em espaço de privação de liberdade deve conhecer as principais técnicas de objetivação da interação humana como ferramenta para refletir sobre sua prática cotidiana. Da mesma forma, por ser uma das poucas pessoas com as quais esse aluno tem contato, o professor precisa atentar-se à maneira como é percebido/notado pelo reeducando e a valorização que emana nesse contexto específico.

Assim como em qualquer campo educacional, onde o docente tipifica seus alunos e também é tipificado por eles, em unidades prisionais os reeducandos também contribuem à construção social do docente e "fazem" o professor em certa medida. "É uma experiência incrível, eu gosto muito de estar em sala de aula, de trocar com o aluno experiências... que eu acho que é uma troca, não sou só eu que ensino, mas os alunos me ensinam muito também" (ANA LUISA).

Sobre o processo de construção do docente decorrente de sua práxis, Deleuze (2001) vai ao encontro das ideias de Bourdieu e reafirma que tratase uma aquisição de habitus, de um "devir sujeito" em um mecanismo em que o indivíduo é o próprio hábito, sendo este "a raiz constitutiva do sujeito e, na sua raiz, o sujeito é a síntese do tempo, a síntese do presente e do 
passado à luz do futuro" (DELEUZE, 2001, p. 101). Assim, o habitus pedagógico está imerso e decorre de um campo de interioridade relacionado a dimensões externas; um campo simbólico repleto de urgências de um presente vivo que edificam o devir do eu-docente, mas também de um passado e futuro evidentes.

Esse devir, segundo Deleuze (2003), não se aprende com a imitação de alguém, mas sim junto a alguém, em um processo que vai muito além do que aquilo que se deseja aprender; da mesma forma que não possui um objetivo, uma tendência ao fim, pois

devir é, a partir das formas que se tem, do sujeito que se é, dos órgãos que se possui ou das funções que se preenche, extrair partículas, entre as quais instauramos relações de movimento e repouso, de velocidade e lentidão, as mais próximas daquilo que estamos em vias de tornarmos, e através das quais nos tornamos. É nesse sentido que o devir é o processo do desejo (DELEUZE; GUATTARI, 1980, p. 55).

Trata-se, portanto, de construir novas práticas através das relações sociais que se vivencia, entre diferenças e semelhanças, em um processo aberto, revolucionário. O devir exige traçar novas rotas, assim como o habitus demanda a arquitetura de estratégias, cujo foco é o de sempre evoluir e vivificar a experiência. "Cada aula é um momento diferente de compartilhar saberes relacionando as vivências pessoais, culturais, históricas, sociais e, como consequência, produzindo e reconstruindo novos, a partir daqueles já apresentados e vivenciados" (LUANA). Assim, podemos inferir que um habitus pedagógico que se torna um devir docente é aquilo que se edifica por meio do campo educacional, das relações dialógicas e das interações emergentes.

Ao inserir-se em um espaço de privação de liberdade, o professor, dotado de um habitus pedagógico, precisa construir um devir docente para esse contexto singular, o que exige novos conhecimentos e diferentes percepções do real. Nesse sentido, quando questionada sobre os saberes necessários a um docente que leciona em um ambiente prisional, a professora Luana afirma que 
além do domínio da sua área de atuação, é preciso ter um olhar diferenciado devido às circunstâncias atuais do local onde os alunos estão inseridos. É preciso ter muita empatia, humildade, equilíbrio físico-emocional e muita criatividade e motivação para tornar a aula um processo construtivo de saberes, valorizando as competências individuais que somam e multiplicam no coletivo. Como sempre deixamos claro para os alunos, que não nos importa saber o porquê estão ali, nos interessa apenas que são alunos de direito, que conquistaram a muito custo essa vaga numa imensidão de pedidos e listas de espera, então, por conta disso, a maioria dos alunos valoriza muito essa oportunidade e como consequência torna toda e cada aula única e especial, com múltiplos saberes envolvidos por meio dos conhecimentos compartilhados e reconstruídos! (LUANA).

Ao relatar as necessidades do docente diante desse público específico, a professora também enfatiza a importância da educação nesse ambiente e a valorização do ensino por parte dos reeducandos, o que nos leva a perceber que "as atitudes em respeito da escola, da cultura escolar e do futuro oferecido pelos estudos são, em grande parte a expressão de valores implícitos ou explícitos que eles devem à sua posição social" (BOURDIEU, 2007, p. 46), isto é, existe por parte dos próprios alunos a percepção de uma educação transformadora, pela qual se pode alcançar novos patamares sociais, seja dentro ou fora da unidade prisional.

Percebemos um aspecto importante na fala da professora Luana. Ela relata que sempre deixa claro que não importa saber o porquê de seus alunos estarem ali, mas lembra que a vontade os conduziu nessa luta por uma vaga. Parece-nos uma tentativa de não querer saber, de não querer olhar para a condição em que o aluno se encontra. Não olhar para a origem, no sentido de não querer ter com ela para instituir o que ele pode ou não conseguir aprender. Isso nos lembra o que Rancière (2015) denomina, retomando a concepção freireana, de emancipação

E quem emancipa não tem que se preocupar com aquilo que o emancipado deve aprender. Ele aprenderá o que quiser, nada, talvez. Ele saberá que pode aprender porque a mesma inteligência está em ação em todas as produções humanas, que um homem sempre pode compreender a palavra de um outro homem (RANCIÈRE, 2015, p.37). 
Esse é o princípio de igualdade a partir do qual deve partir o processo educativo. Tal princípio só pode ser garantido quando há um mestre ignorante a ponto de reconhecer seu próprio não saber bem como ignorar aquilo que pode ou sabe seu aluno. Para o autor, pode-se ensinar o que se ignora, desde que se emancipe o aluno. Contudo,

para emancipar um ignorante, é preciso e suficiente que sejamos, nós mesmos, emancipados" (...) O ignorante aprenderá sozinho o que o mestre ignora, se o mestre acredita que ele o pode, e o obriga a atualizar sua capacidade (RANCIÈRE, 2015, p.34- 35).

Se o círculo da impotência liga o aluno ao explicador, o círculo da potência reforça a importância do mestre que acredita na capacidade de seu aluno de aprender por si mesmo. Na fala da professora Luana, destacamos três palavras que nos chamam atenção: é preciso ter empatia, humildade e motivação. Há uma tentativa de aproximação com esse aluno pela empatia, a humildade de se perceber como igual a ele e a motivação para acreditar que ele é capaz.

Delineia-se, então, a expansão do círculo da potência e a proclamação da "igualdade de inteligências" entre educador e educando:

Quem ensina sem emancipar, embrutece. E quem emancipa não tem que se preocupar com aquilo que o emancipado deve aprender. Ele aprenderá o que quiser, nada, talvez. Ele saberá que pode aprender porque a mesma inteligência está em ação em todas as produções humanas, que um homem sempre pode compreender a palavra de um outro homem (RANCIÈRE, 2015, p. 16).

Como escrevem Nunes e Leite (2019), entender a fala das pessoas historicamente silenciadas e como podem se tornar protagonistas, como podem ser registradas e consideradas pelos professores, direciona-nos ao princípio da educação freireana, a saber, de um movimento emancipatório, que liberte educando e educador em ações coletivas e solidárias.

Esta compreensão perpassou o processo de escuta das vozes docentes, emanadas a partir de um habitus pedagógico especificamente delicado, onde uma pluralidade de outras vozes ainda ecoam. Para que não reverberem no silêncio do cárcere, espaço de segregação social por natureza, é necessário que relembremos sempre que a igualdade de 
oportunidades - esse imperativo - demanda a igualdade de inteligências de que nos fala Rancière. Afinal, a ressocialização do sujeito não será efetiva enquanto não estivermos escutando (ou compreendendo) as palavras destes sujeitos.

\section{À guisa de conclusão}

Mobilizando interlocuções acerca dos desafios de saberes e sujeitos frente ao discurso de igualdade de oportunidades no atendimento educacional em privação de liberdade, buscamos o enfoque organizador da multirreferencialidade para ajustar o olhar ao papel dos docentes. Procuramos, a partir de vozes testimoniais que levaram às práticas educacionais nas estruturas sociais que emergem do contexto de privação de liberdade, instigar reflexões e fornecer subsídios à construção de um habitus pedagógico mais inclusivo, um devir mais sintonizado com as concepções emancipatórias de educação e sociedade.

$\mathrm{Na}$ complexa relação multirreferencial entre sujeitos e saberes, dentro das ainda mais complexas políticas educacionais e curriculares que regimentam as práticas docentes, a busca por espaços mais inclusivos, acessíveis e democráticos requer que repensemos nossa práxis, nosso devir, nosso habitus pedagógico. Através da análise da multiplicidade das falas, evocadas por sujeitos igualmente múltiplos e a partir do contexto de atuação docente no habitus pedagógico com a especificidade da privação de liberdade, percebemos que o concepção emancipatória de educação mobiliza saberes e sujeitos no sentido da expansão do círculo da potência, trazendo para a base desta práxis os princípios democráticos - e, portanto, inclusivos - por excelência. Talvez mais que matrizes curriculares, artigos de lei e regimentos internos, esta concepção de educação e de sociedade pode garantir o atendimento minimamente satisfatório às diferenças: pedagogicamente, organizacionalmente, politicamente e socialmente. 


\section{Referências}

ARDOINO, J. Abordagem multirreferencial (plural) das situações educativas e formativas. In. BARBOSA, J. G. (org). Multirreferencialidade nas ciências e na educação. São Carlos: EdUFSCar, 1998.

BARBOSA, J. G.; RIBEIRO, M. R. F. Abordagem multirreferencial e formação autoral. Revista Observatório, v. 5, n. 1, p. 38-73, 14 jan. 2019. Disponível em: https://sistemas.uft.edu.br/periodicos/index.php/observatorio/article/downlo ad/6462/14690/. Acesso em: 29 jul. 2019.

BRASIL. Conselho Nacional de Educação. Diretrizes Nacionais para a Oferta de Educação para Jovens e Adultos em Situação de Privação de Liberdade. Resolução CNE/CEB 2/2010. Diário Oficial da União, Brasília, 20 de maio de 2010.

BOURDIEU, P. Pierre Bourdieu avec Löic Wacquant; réponses. Paris: Sevil, 1992.

BOURDIEU, P. Esboço de uma teoria prática. In: ORTIZ, R. (org.). Pierre Bourdieu. São Paulo: Ática, 1994.

BOURDIEU, P. Questões de sociologia. Lisboa: Fim de Século, 2003.

BOURDIEU, P. Os usos sociais da ciência: por uma sociologia clínica do campo científico. São Paulo: UNESP, 2004.

BOURDIEU, P. A Escola conservadora: as desigualdades frente à escola e à cultura. In: NOGUEIRA, M. A.; CATANI, A. (org.). Escritos de Educação.

Petrópolis/RJ: Vozes, 2007.

BOURDIEU, P. O Senso prático. Petrópolis: vozes, 2009.

BOURDIEU, P.; CHARTIER, R. O sociólogo e o historiador. (Trad. Guilherme João de Freitas Teixeira com a colaboração de Jaime A. Clasen). Belo Horizonte: Autêntica Editora, 2012.

CANDAU, V. M. (1992). Universidade e formação de professores: que rumos tomar. In. CANDAU, V. M. (Org.). Magistério: construção cotidiana (p. 31-68). Petrópolis: Vozes.

CASTORIADIS, C. As encruzilhadas do Labirinto III: o mundo fragmentado, Rio de Janeiro, Paz e Terra, 1992.

DELEUZE, G.; GUATTARI, F. Qu'est-ce que la philosophie?. Les Éditions de Minuit, Paris, 1991. 
DELEUZE, G.; GUATTARI, F. Mil Platôs. Vol. 4, Editora 34. São Paulo, 1980.

DELEUZE, G. Conversações. São Paulo: Editora 34, 1992.

DELEUZE, G. En Medio de Spinoza. Buenos Aires: Cactus, 2008.

DELEUZE, G. Diferença e Repetição. Tradução de Luiz Orlandi e Roberto Machado, prefácio de José Gil. Relógio D'Água, 2000.

DELEUZE, G. Empirismo e subjetividade: ensaio sobre a natureza humana segundo Hume. Tradução de Luiz Orlandi. São Paulo: Ed. 34, 2001. (Coleção TRANS).

DELEUZE, G. A ilha deserta e outros textos. São Paulo: Editora lluminuras, 2004.

DELEUZE, G. Proust e os signos. 2.ed. Trad. Antonio Piquet e Roberto Machado. Rio de Janeiro: Forense Universitária, 2003.

FOUCAULT, M. Vigiar e Punir: nascimento da prisão. Rio de Janeiro: Vozes, 2009.

FREIRE, P. Pedagogia da autonomia: saberes necessários à prática educativa. São Paulo: Paz e Terra, 1996.

FRÓES BURNHAM, T. Complexidade, multirreferencialidade, subjetividade: três referências polêmicas para a compreensão do currículo escolar. Em Aberto, Brasília, v. 12, n. 58, p. 3-13, 1993. Disponível em:

http://rbepold.inep.gov.br/index.php/emaberto/article/view/1885/1856. Acesso em: 28 jul. 2019.

FRÓES BURNHAM, T.; FAGUNDES, N. C. Transdisciplinaridade, Multirreferencialidade e Currículo. Revista da FACED, Salvador, Bahia, v. 5, p. 39-55, 2002. Disponível em:

https://repositorio.ufba.br/ri/bitstream/ri/1386/1/2013.pdf. Acesso em: 29 jul. 2019.

GARCIA, F. M.; SOUZA, G. M. Educação aos privados de liberdade no Amazonas: correntezas de um direito. Revista Exitus, Santarém, v. 9, p. 746774, 2019. Disponível em: http://www.ufopa.edu.br/revistaexitus. Acesso em: 01 de jun. 2020.

GOES DENARDI, V.; ROHDEN, F. A.; LEAL, A. R.; AMBRÓZIO, N. D. Projeto Despertar pela Leitura no Complexo Penitenciário de Florianópolis-SC: Abordagens teóricas e metodológicas. Revista Interinstitucional Artes de Educar. Rio de Janeiro, V. 5, N.1, 2019, pág. 87-102. Disponível em: https://www.e-publicacoes.uerj.br/index.php/riae/article/view/39561/29620. Acesso em: 20 jul. 2019. 
MARTINS, J. B. A noção de identidade e o olhar multirreferencial: colocando algumas questões para a educação!. PSI. Revista de Psicologia Social e Institucional, Londrina, v. 1, n.2, p. 169-188, 1999. Disponível em: http://www.vel.br/ccb/psicologia/revista/jb.htm. Acesso em: 29 jul. 2019.

MARTINS, J. B. Contribuições epistemológicas da abordagem multirreferencial para a compreensão dos fenômenos educacionais. Revista Brasileira de Educação, São Paulo, v. 26, p. 85-94, 2004. Disponível em: http://www.scielo.br/pdf/rbedu/n26/n26a06.pdf. Acesso em 30 jul. 2019.

NUNES, A. A. de S.; LEITE, S. F. A fala dos excluídos em tempos líquidos. Revista Exitus, Santarém, v. 9, p. 505-528. Disponível em:

http://www.ufopa.edu.br/revistaexitus. Acesso em: 01 de jun. 2020.

RANCIÈRE, J. O mestre ignorante: cinco lições sobre a emancipação intelectual. Trad: Lílian do Valle. 3ed. Belo Horizonte: Autêntica Editora, 2015.

SILVA, V. A.; CARDOZO, P. F. Os desafios das práticas curriculares em contextos diversificados: o caso dos refugiados sírios nas escolas brasileiras. Revista Exitus, Santarém, v. 10, p. 1-28, 2020. Disponível em: http://www.ufopa.edu.br/revistaexitus. Acesso em: 01 de jun. 2020.

TEIVE, G. M. G. Uma vez normalista, sempre normalista: Cultura escolar e produção de um habitus pedagógico (Escola Normal Catarinense: 1911 a 1935). Florianópolis: Editora Insular, 2008.

TOLEDO, E. J. D. L.; COUTINHO, H. D. N. Licenciatura: escolha ou falta de opção. Revista Exitus, Santarém, v. 10, p. 20-29, 2020. Disponível em: http://www.ufopa.edu.br/revistaexitus. Acesso em: 01 de jun. 2020.

Recebido em: 15 de fevereiro de 2020

Aprovado em: 10 de junho de 2020

Publicado em: 02 de setembro de 2020 